\title{
Determination of particle size, surface area, and shape of supplementary cementitious materials by different techniques
}

\author{
Eleni C. Arvaniti - Maria C. G. Juenger · Susan A. Bernal · Josée Duchesne • \\ Luc Courard · Sophie Leroy • John L. Provis • Agnieszka Klemm • \\ Nele De Belie
}

Received: 2 May 2014/ Accepted: 26 September 2014/Published online: 4 October 2014

(C) RILEM 2014

\begin{abstract}
The particle size distribution, surface area and shape are fundamental characteristics of supplementary cementitious materials (SCMs). Accurate measurement of these properties is required in computational efforts to model the hydration process, and the characterization of these parameters is also an important practical issue during the production and use of blended cements. Since there are no standard procedures specifically for the determination of physical properties of SCMs, the techniques that are currently used for characterizing Portland cement are applied to SCMs. Based on the fact that most of the techniques have been developed to measure cements, limitations occur when these methods are used for other materials than cement, particularly when these have lower fineness and different particle shape and
\end{abstract}

E. C. Arvaniti · N. De Belie $(\bowtie)$

Magnel Laboratory for Concrete Research, Department of Structural Engineering, Faculty of Engineering and Architecture, Ghent University, Technologiepark

Zwijnaarde 904, 9052 Ghent, Belgium

e-mail: nele.debelie@ugent.be

M. C. G. Juenger

Department of Civil, Architectural and Environmental Engineering, University of Texas at Austin, 301 E. Dean Keeton St. C 1748, Austin, TX 78712, USA

\section{S. A. Bernal · J. L. Provis}

Department of Materials Science and Engineering, University of Sheffield, Sheffield S1 3JD, UK mineralogical composition. Here, samples of fly ash, granulated blast furnace slag and silica fume were tested. Different results obtained using several methods for the determination of specific surface area are presented. Recommendations for testing SCMs using air permeability, sieving, laser diffraction, BET, image analysis and MIP are provided, which represent an output from the work of the RILEM Technical Committee on Hydration and Microstructure of Concrete with Supplementary Cementitious Materials (TC-238-SCM).

Keywords Supplementary cementitious materials . Fineness - Sieve - Laser diffraction - Blaine - BET . Image analysis $\cdot$ Mercury intrusion porosimetry

\author{
J. Duchesne \\ Département de géologie et de génie géologique, \\ Université Laval, Pavillon Adrien-Pouliot, local 4507, \\ 1065, ave de la Médecine, Quebec, QC G1V 0A6, Canada \\ L. Courard · S. Leroy \\ GeMMe Research Group, ArGEnCo Department, \\ University of Liege, Liege, Belgium
}
A. Klemm
Department of Construction and Surveying, School of Engineering and Built Environment, Glasgow Caledonian University, Cowcaddens Road, Glasgow G4 0BA, UK 


\section{Introduction}

The use of supplementary cementitious materials (SCMs) such as fly ash, blast furnace slag, and silica fume in the concrete industry has increased worldwide over the past decades [1]. They are added to concrete as part of the total cementitious system, as a partial replacement of Portland cement. The use of SCMs in concrete production is desirable both for emission reduction and energy conservation as well as for the improvement of concrete mechanical and durability properties [2]. SCMs are mostly by-products of industrial processes [3] and in most cases the quality of these materials is less controlled during their production than in the direct production of a primary product from a purpose-designed process, resulting in materials with varied characteristics [4].

The performance of SCMs in concrete is strongly dependent on their physical, mineralogical and chemical characteristics, which vary depending on the nature and source of the SCMs. In a recent review [5] of the available techniques that are currently used for the determination of fineness of SCMs, it was identified that the standardized methods developed for Portland cement characterization are usually applied to SCMs without any adaptation. These methods include sieving analysis, air-permeability test (Blaine), nitrogen sorption with Brunauer-EmmettTeller (BET) analysis, laser diffraction (LD), and image analysis. Detailed information of the principles of each of these techniques and their application to SCMs is given in [5]. In the context of the present study, a brief overview of the available standards or recommendations for each of the methods mentioned previously is given:

The European Standard EN 196-6 [6] describes the dry sieving method for the determination of the retention on sieving of particles which substantially pass a $2.0 \mathrm{~mm}$ test sieve. ASTM C430 [7] standard gives an alternative wet sieving method for the determination of fineness of hydraulic cement based on the retained material on the no. 325 sieve $(45 \mu \mathrm{m}$ opening size). A specific standard for the determination of fineness of fly ash by wet sieving method is the EN 451-2 [8] standard.

Blaine fineness is determined by the air-permeability test and is a single parameter that is meant to characterize the fineness of a cement powder. Two updated standards are currently used applying this technique, the American Standard ASTM C204-11 [9] and the European Standard EN 196-6 [6]. This method assumes that the particles are spherical and that the compacted bed formed is uniform. For the calibration of the apparatus, ASTM C204-11 indicates that a standard reference material from the series of SRM 114 should be used.

Laser diffraction is a standardized method according to the International Standard ISO 13320 [10] and is used for the determination of particle size distributions. Two methods are used, the dry and wet method, depending on the nature of the dispersant medium. The method assumes that the particles are spherical, and the optical parameters of the testing material are also required to collect reliable results. The particle size range that can be measured using this method is related to the instruments characteristics. The latest commercial instruments can measure particle sizes from 0.01 to $3,500 \mu \mathrm{m}$.

The determination of the specific surface area of solids by gas adsorption-BET method, is a standardized method and it is described in ISO 9277 [11]. This method requires the pre-conditioning of the samples at a given temperature in helium or nitrogen flow, referred to as outgassing, to minimize the interferences in the measurements due to gases and vapors that can be physically adsorbed on the surface of the particles. Outgassing is one of the main factors inducing variability in the results collected using this technique [5].

Image analysis is another method for the measurement of particle size distributions. The International Standard ISO 13322-1 [12] gives a standardized description of the static image analysis method and its validation. This standard includes methods of calibration verification using a certified standard graticule as a reference. The measurement precision is correlated to the number of analyzed particle images and the analysis window in order to make sure that the obtained information is valid. It is also clearly stated that care has to be taken in order to ensure that the analysis is representative of the bulk sample as only a small amount of sample is examined. In order to have a representative sample prior to analysis the original sample is splitted and measurements are performed on three or more parts. Statistical analysis of the data shows if the samples differ systematically.

Mercury intrusion porosimetry (MIP), which is a standardized method that is generally used for the 
determination of the pore size distribution, is introduced in this study as a potential method that can also be used for the determination of particle size distribution of SCMs. Particle size distribution (PSD) by MIP is derived from Mayer and Stowe's [13] relationship established between particle size and breakthrough pressure required to fill the interstitial voids between a packed bed of spheres. Following the development of PSD by MIP, Mayer and Stowe presented the benefits of the spherical model for characterising certain types of porous solids, over that of the cylindrical model [14].

However, the standard methods used to determine particle characteristics for cement may not be as accurate when applied to SCMs. For instance, the air permeability test for specific surface area (Blaine), which is widely used for characterizing Portland cements [15], relies on the assumptions that there is a relatively limited range of particle sizes in the material, with consistent inter-particle interactions, and that there are available, internationally accepted reference powders with properties similar to the material of interest. In addition to the fact that these conditions may not apply for all SCMs, the lack of an appropriate reference material is also a restraining factor for this technique [5].

The objective of this paper is to determine the physical properties of selected SCMs, in order to identify the factors that induce variations in the results obtained from the different techniques, and suggest the most suitable techniques and methods that can be applied to physically characterize SCMs.

\section{Materials and methods}

\subsection{Materials}

Two batches of commercially available fly ash (FA1, FA2), two ground granulated blast furnace slags (BFS1, BFS2), and a densified silica fume (SF), were used to demonstrate the methods and techniques discussed in this paper. The chemical compositions of the materials are presented in Table 1 . The chemical analysis was performed by X-ray fluorescence (XRF), and the loss on ignition (LOI), sulfate content, chloride content and the sodium oxide equivalent $\left(\mathrm{Na}_{2} \mathrm{O}_{\text {eq }}\right)$ content were determined according to $\mathrm{EN}$ 196-2 [16]. The free calcium oxide content was
Table 1 Chemical composition of the materials used in this study, determined via X-ray fluorescence

\begin{tabular}{lcclll}
\hline $\mathrm{wt} \%$ & $\mathrm{FA} 1$ & $\mathrm{FA} 2$ & $\mathrm{BFS} 1$ & $\mathrm{BFS} 2$ & $\mathrm{SF}$ \\
\hline $\mathrm{SiO}_{2}$ & 54.19 & 51.37 & 36.37 & 33.86 & 95.60 \\
$\mathrm{Al}_{2} \mathrm{O}_{3}$ & 23.5 & 28.71 & 9.83 & 8.91 & 0.34 \\
$\mathrm{Fe}_{2} \mathrm{O}_{3}$ & 7.92 & 5.10 & 0.26 & 0.69 & 0.11 \\
$\mathrm{CaO}$ & 3.02 & 3.56 & 41.24 & 42.64 & 0.23 \\
$\mathrm{MgO}$ & 1.92 & 1.01 & 7.41 & 7.39 & 0.37 \\
$\mathrm{Na}_{2} \mathrm{O}$ & 1.08 & 0.29 & 0.28 & 0.28 & 0.28 \\
$\mathrm{~K}_{2} \mathrm{O}$ & 3.38 & 1.77 & 0.41 & 0.52 & 0.92 \\
$\mathrm{P}_{2} \mathrm{O}_{5}$ & 0.27 & 0.64 & - & - & 0.08 \\
$\mathrm{SO}_{3}$ & 0.94 & 1.11 & 1.62 & 1.62 & 0.28 \\
$\mathrm{Cl}^{-}$ & 0.003 & 0.001 & 0.02 & 0.01 & - \\
$\mathrm{Reactive}_{\mathrm{SiO}}$ & 41.86 & 37.48 & - & - & - \\
Free CaO & 0.1 & $<0.1$ & - & - & - \\
Na-equivalent & 3.31 & 1.46 & 0.28 & 0.28 & - \\
LOI & 1.84 & 3.6 & 1.3 & - & 1.66 \\
Density $\left(\mathrm{g} / \mathrm{cm}^{3}\right)$ & 2.136 & 2.221 & 2.784 & 2.924 & 2.217 \\
\hline
\end{tabular}

Loss on ignition (LOI) was determined at $1,000{ }^{\circ} \mathrm{C}$

determined according to EN 451-1 [17], and the reactive silicon dioxide content according to EN 197-1 [18].

Scanning electron micrographs, collected using a JSM 7100, JEOL, microscope, at an acceleration voltage of $2 \mathrm{keV}$, and a working distance of $8 \mathrm{~mm}$, are provided in Fig. 1, as a qualitative indication of the morphology of the SCMs under investigation. The fly ash and silica fume particles are generally spherical, whereas the BFS particles are angular and irregularly shaped.

\subsection{Methods}

\subsubsection{Sieving test}

Wet-sieve analyses of the fly ashes, slags, and silica fume were performed following the procedures described in ASTM C430 [7]. A $1.000 \mathrm{~g}$ sample of the SCM tested was placed on a clean, dry $45 \mu \mathrm{m}$ (No. 325) sieve, and then a gentle stream of water was passed through to wet the sample. The water spray nozzle was then adjusted to $69 \pm 4 \mathrm{kPa}$ with the bottom of the nozzle about $12 \mathrm{~mm}$ from the top of the sieve frame. The sample was washed for $1 \mathrm{~min}$, moving the sieve with a circular motion in a horizontal plane at the rate of one motion per second in the spray. 


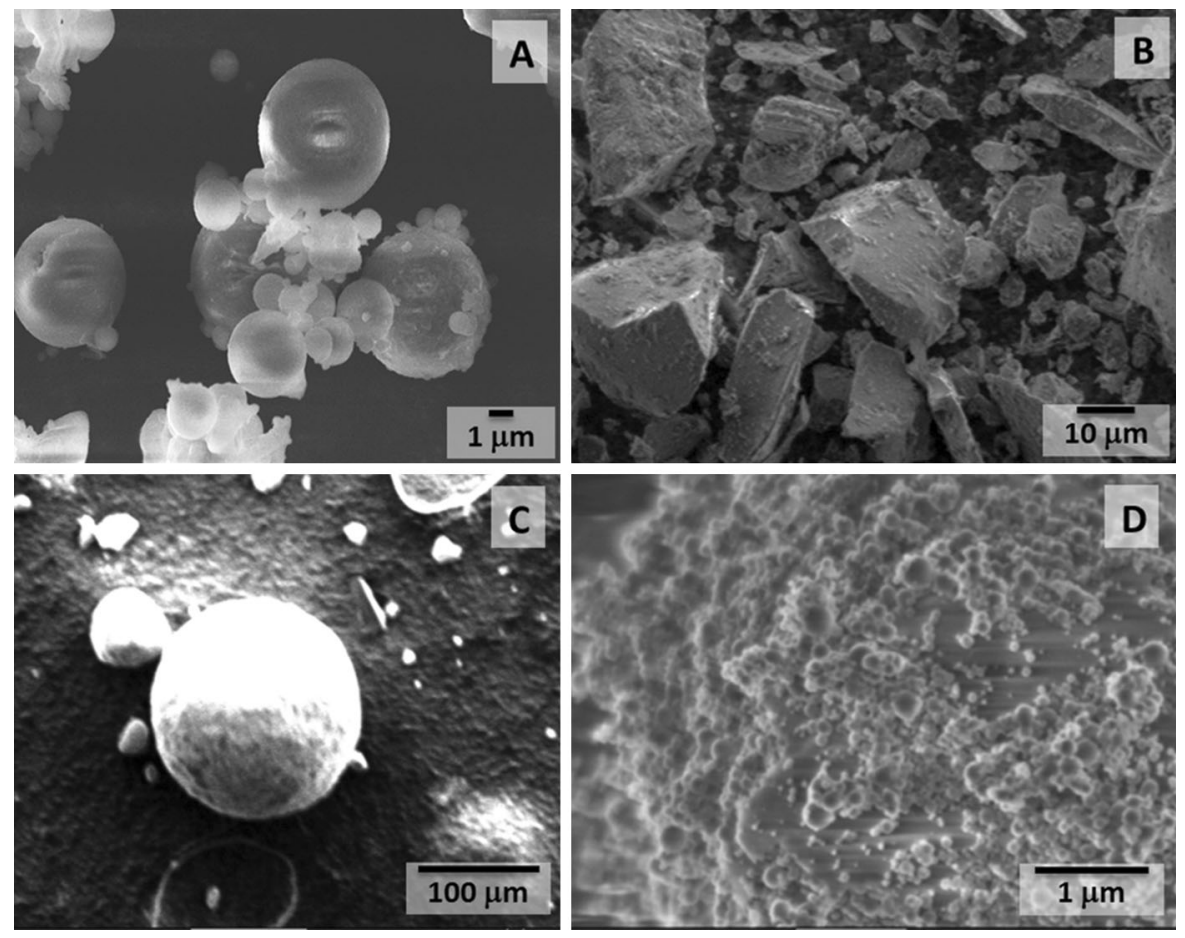

Fig. 1 Scanning electron microscope micrographs of: A fly ash particles (spherical); B slag particles (irregular); C and D densified silica fume agglomerates (spherical porous particles)

Immediately upon removing the sieve from the spray, the sample in the sieve was rinsed once with about $50 \mathrm{~cm}^{3}$ of deionized water, then the lower surface of the sieve was blotted gently using a damp cloth. The sieve and sample residue were dried on a hot plate, where the sieve was supported in a manner that air could pass freely beneath it, and then cooled. The residue was weighed after being brushed from the sieve.

\subsubsection{Blaine test}

The air permeability test was performed according to the method described in the European Standard EN 196-6 [6]. In this standard procedure, the pycnometer method for the determination of the density of the SCMs is also described.

\subsubsection{BET testing}

Nitrogen adsorption-desorption measurements were carried out at $77 \mathrm{~K}$ on a Micromeretics Tristar 3000 apparatus to determine the Brunauer-Emmett-Teller
(BET) surface area. Before measurement, samples were kept in a desiccator until testing. Samples were cooled with liquid nitrogen and analyzed by measuring the volume of gas $\left(\mathrm{N}_{2}\right)$ adsorbed at specific pressures. The pore volume was taken from the adsorption branch of the isotherm at $P_{\mathrm{i}} / P_{0}=0.95$ assuming complete pore saturation.

\subsubsection{Laser diffraction}

LD analysis was performed on a Mastersizer 2000E (Malvern Instruments, Malvern, UK; $633 \mathrm{~nm}$ red laser) with a Hydro 2000SM wet unit (50-120 mL). The manufacturer specifications state that this instrument is capable of measuring powders with a size distribution ranging from 0.1 to $1,000 \mu \mathrm{m}$. The chosen dispersant was isopropanol (IPA). The sample is insoluble in IPA and the dispersant does not react with the sample itself. An external ultrasonic bath $(35 \mathrm{kHz}$, $320 \mathrm{~W}$ ) was used for the de-agglomeration of the particles, increasing the dispersion efficiency. The refractive index of IPA was set at 1.39 [19]. A suitable method was developed for the determination of 
particle size distribution of each of the SCMs evaluated using the light scattering technique. This is described in the Sect. 3.

\subsubsection{Image analysis testing}

Static image analysis was performed by means of the Occhio 500 Nano image analyzer. This instrument includes an integrated vacuum dispersion system and a high-quality optical component which allows assessment of size and shape of a set of dispersed particles. A few milligrams of particles were dispersed onto a circular glass slide which is moved above a collimated blue $(490 \mathrm{~nm})$ LED backlighting. Pictures of individual particles were captured with a $1,392 \times 1,040$ pixels video camera fitted with a telecentric lens. The system routinely determined the magnification through the imaging of a calibrated grid and the working resolution was determined as $0.563 \mu \mathrm{m} /$ pixel. The inscribed disk diameter $\left(D_{\mathrm{IN}}\right)$ of each particle is calculated in real time to build size distribution curves weighted by apparent volume (PSD-V) [20], making the assumption that particles have identical densities and flatness ratios, whatever their size.

The particle image acquisition method proceeds by scanning the first 50,000 particles, ensuring that particles are scanned at least once on the whole diameter of the glass slide. The accuracy associated with the estimation of PSD-V, expressed as the twosided $95 \%$ confidence interval, is computed by the bootstrap method $[20,21]$.

\subsubsection{Mercury intrusion porosimetry (MIP)}

The porosimeter used was an AutoPore IV 9500 by Micromeritics, with in-built Mayer-Stowe data reduction pack. A base filling pressure of $3.4 \mathrm{kPa}$ is employed to fill the interstitial voids surrounding the collective sample (undulations across the 'surface' of the grouped specimen). This pressure will fill voids of $360 \mu \mathrm{m}$ - either interstitial or interparticle [22]. This then forms the 'zero' value from which the analysis proceeds. Samples were first dried in an oven at $75{ }^{\circ} \mathrm{C}$, for around $2 \mathrm{~h}$, subsequently acclimatised in a desiccator to minimise moisture uptake from the environment during cooling. The penetrometer type employed was "3 Bulb, 1.190 Stem, Powder".

\section{Results and discussion}

\subsection{Determination of particle size by sieving}

The fly ashes tested pass the ASTM C618 [23] fineness criterion for fly ash and natural pozzolans, with less than $34 \%$ of the material retained on the $45 \mu \mathrm{m}$ sieve; the blast furnace slags passed the ASTM C989 [24] fineness criterion with less than $20 \%$ of the material retained on the $45 \mu \mathrm{m}$ sieve. Silica fume was not tested using this method because the criteria established are only for fly ash and natural pozzolans. Sieve analysis is not an appropriate test method for assessing fineness of silica fume.

The results of the wet-sieve analysis are shown in Table 2. The BFS1 sample had clumps of particles retained on the sieve after testing, as shown in Fig. 2. It can be concluded that clumping of particles causes potentially erroneous results. It is clear that materials should be adequately dispersed before testing, a step which is not specified in the ASTM C430 [7] standard.

\subsection{Surface area by air permeability}

In order to measure the surface area by the airpermeability test, knowledge of the density of the material is needed. The density (Table 1) for the five materials tested was measured by the pycnometer method. The test in this study was performed according to the European Standard EN 196-6 [6]. When applying the air-permeability method to the SCMs, problems occur during the procedure. In the case of blast furnace slag, by using the mass as determined in Eq. 1 in EN 196-6, the adjusted thumb pressure on the plunger (Fig. 3) is not sufficient to form a bed of porosity 0.500 as required by the standards. In this case, samples of different mass values were prepared to produce a test bed with porosity of $0.530 \pm 0.005$, as calculated using Eq. 8 of EN 196-6.

In the case of densified silica fume it was impossible to prepare a compacted bed of porosity 0.500 (Fig. 4B, C) following the typical procedure as it is described in the EN196-6 standard. While the pressure applied by the finger was released, the bed initially formed responded semi-elastically and expanded again to become unpacked. The time measured in the Blaine apparatus was in the range of a few seconds (2-3 s) which could not be considered as accurate. 
Table 2 Results of the mass used for the formation of the bed of porosity e and the specific surface area of SCMs measured using the traditional and the modified plunger

\begin{tabular}{|c|c|c|c|c|c|c|c|c|c|c|}
\hline \multicolumn{9}{|l|}{ Blaine } & \multirow{3}{*}{$\begin{array}{l}\text { Wet sieving } \\
\% \text { retained } \\
\text { on sieve }\end{array}$} & \multirow{3}{*}{$\begin{array}{l}\text { BET } \\
\text { Specific } \\
\text { surface } \\
\text { area SSA } \\
\left(\mathrm{m}^{2} / \mathrm{kg}\right)\end{array}$} \\
\hline \multirow{2}{*}{$\begin{array}{l}\text { Sample } \\
\text { ID }\end{array}$} & \multicolumn{4}{|c|}{ Original plunger } & \multicolumn{4}{|c|}{ Modified plunger } & & \\
\hline & $\begin{array}{l}\text { Calculated } \\
\text { mass }(\mathrm{g})\end{array}$ & $\begin{array}{l}\text { Measured } \\
\text { mass (g) }\end{array}$ & $e$ & $\begin{array}{l}\text { Specific } \\
\text { surface } \\
\text { area SSA } \\
\left(\mathrm{m}^{2} / \mathrm{kg}\right)\end{array}$ & $\begin{array}{l}\text { Calculated } \\
\text { mass }(\mathrm{g})\end{array}$ & $\begin{array}{l}\text { Measured } \\
\text { mass (g) }\end{array}$ & $e$ & $\begin{array}{l}\text { Specific } \\
\text { surface } \\
\text { area SSA } \\
\left(\mathrm{m}^{2} / \mathrm{kg}\right)\end{array}$ & & \\
\hline FA1 & 2.0056 & 2.0056 & 0.50 & 253 & 2.1060 & 2.1063 & 0.50 & 240 & 20.82 & 452 \\
\hline FA2 & 2.0859 & 2.0861 & 0.50 & 367 & 2.1903 & 2.1902 & 0.50 & 387 & 14.67 & 560 \\
\hline BFS1 & 2.6142 & 2.5506 & 0.51 & 373 & 2.7451 & 2.6502 & 0.52 & 369 & 11.31 & 1025 \\
\hline BFS2 & & & & & & & & & 1.52 & 721 \\
\hline SF & 2.0822 & - & - & - & 2.1864 & - & - & - & - & 17102 \\
\hline
\end{tabular}

Percent of material passing the no. $325(45 \mu \mathrm{m})$ sieve on wet-sieving following ASTM C430. Specific surface area measured by BET method

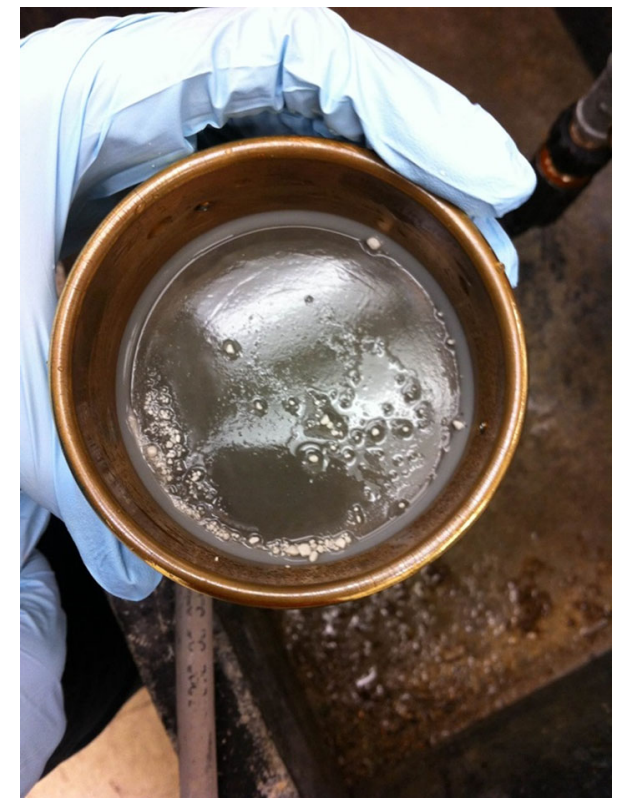

Fig. 2 BFS1 retained on no. $325(45 \mu \mathrm{m})$ sieve after wetsieving following ASTM C 430

A modified plunger was prepared which was perforated in the bottom surface, as shown in Fig. 5. This modification was introduced by Teipel and Winter [25] in order to avoid the dust that is produced when the plunger is removed from the permeability cell (Fig. 4B) prior to measurement. The modified plunger does not need to be removed ensuring the compacted bed formation.
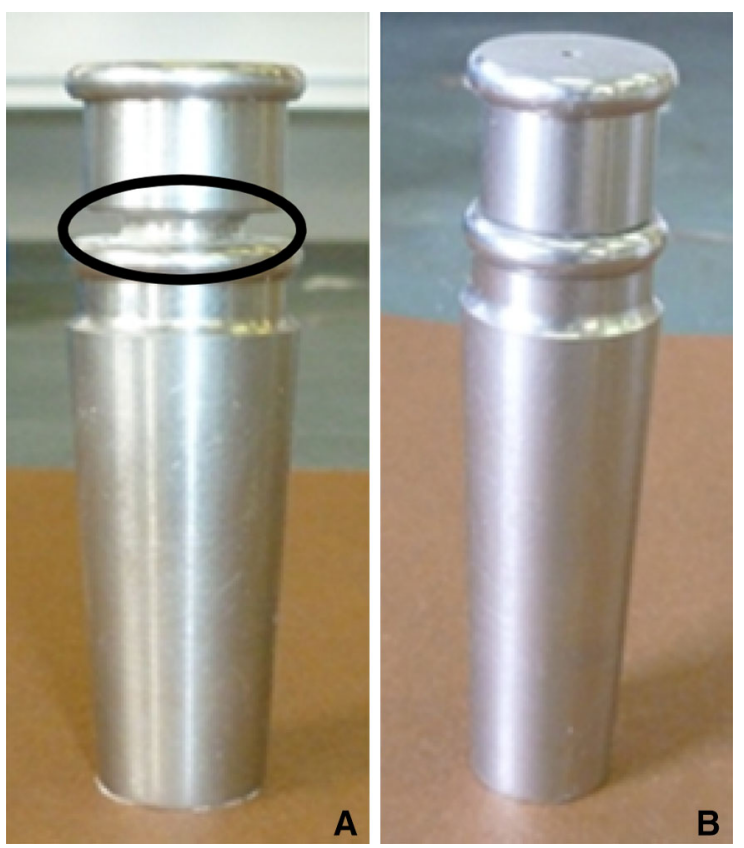

Fig. 3 A Plunger not in contact with the top of the container (cylinder inside diameter $12.70 \pm 0.10 \mathrm{~mm}$ ) when blast furnace slag is measured, B perfect contact plunger with-top of container

The apparatus was calibrated for both plungers in order to determine the $K$ value in Eq. $2\left(S=\frac{K}{\rho} \times\right.$ $\left.\frac{\sqrt{e^{3}}}{(1-e)} \times \frac{\sqrt{t}}{\sqrt{10 \times \eta}}\right)$ in EN 196-6. Since for the case of SCMs an internationally accepted reference material is not yet available, three standard reference materials, Ref. 

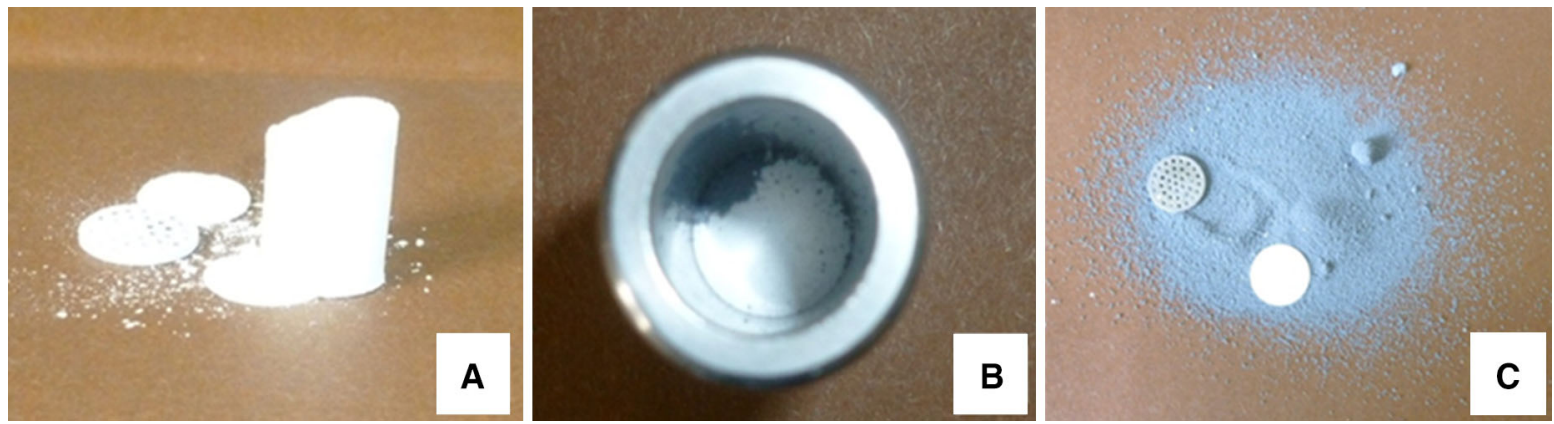

Fig. 4 A Compacted bed of blast furnace slag. Compacted bed of silica fume, $\mathbf{B}$ in the container after removing the plunger and $\mathbf{C}$ out of the container

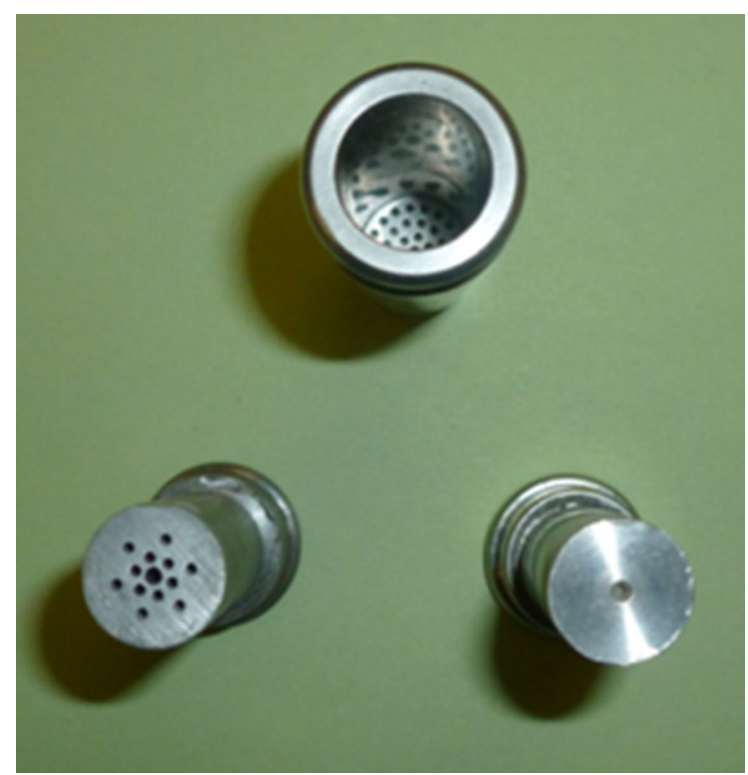

Fig. 5 Traditional (right) and modified (left) perforated plunger according to Teipel and Winter [25]

Table 3 Specific surface areas of the standard reference materials

\begin{tabular}{llll}
\hline Quartz & Ref. 1 & Ref. 2 & Ref. 3 \\
\hline $\begin{array}{l}\text { Specific surface area } \\
\left(\mathrm{cm}^{2} / \mathrm{g}\right)\end{array}$ & 2,750 & 4,030 & 2,950 \\
Calibration & & & \\
Volume $\left(\mathrm{cm}^{3}\right)$ & 1.865 & 1.878 & 1.890 \\
& $( \pm 0.007)$ & $( \pm 0.007)$ & $( \pm 0.005)$ \\
$K$ & 22.90 & 22.51 & 23.81 \\
\hline
\end{tabular}

Calculated volume, and $K$ value for each of the reference materials using the traditional plunger
1, Ref. 2 and Ref. 3, of quartz were used, which each had a density of $2.65 \mathrm{~g} / \mathrm{cm}^{3}$ and porosity $e=0.50$, only differing in specific surface areas (Table 3). The determination of the volume of the permeability cell was conducted using mercury as described in EN1966. For the calibration of the apparatus it was difficult to obtain two values of the volume differing by less than $0.005 \mathrm{~cm}^{3}$ as mentioned in the standard procedure.

The second standard quartz reference material, Ref. 2 (Materialprüfanstalt für Steine und Erden) was used for the calibration of the apparatus by both traditional and modified plungers. This reference material had a specific surface area closer to the SCMs under investigation. Calibrating the apparatus with the original plunger gave a $K$ value of 22.51 $\left(V=1.878 \pm 0.007 \mathrm{~cm}^{3}\right)$. The modified plunger gave a $K$ value of $25.02\left(V=1.972 \pm 0.017 \mathrm{~cm}^{3}\right)$.

After calibration, Eq. $1(m=0.500 \times \rho \times V)$ in EN 196-6 was used to calculate the mass in order to form a bed of specific porosity. By using the calculated mass it was impossible to obtain a good contact of the plunger with the top surface of the permeability cell. Therefore this mass was modified by trial and error using Eq. $8(m=(1-e) \times \rho \times V)$ of EN 196-6. In some cases the porosity of the bed was increased, as shown in Table 3.

The results of the specific surface area measured for each material are shown in Table 2; the measured SSA values do not change significantly $( \pm 5 \%)$ when the measurement is conducted using the modified plunger. For the silica fume no results were obtained since it was impossible to form a well compacted bed, as noted above. 


\subsection{Surface area by BET}

The surface area of the powders as determined by BET method are presented in Table 2. In all cases the measured SSA by the BET method is higher than the one measured by Blaine. The difference between the surface areas measured by Blaine (Table 2) and BET could be attributed to the porosity and surface roughness of the particles. BET surface area is determined by the monolayer coverage of the exposed (pores and cracks included) surface of the particles by nitrogen molecules. If the particles are porous (including multi-particle agglomerates), or have a rough surface structure, the BET surface area will be greater than the Blaine surface area.

\subsection{Particle size distribution by laser diffraction}

\subsubsection{Method development}

Before using a measurement technique for routine analysis, it is necessary to develop a reliable methodology that maximizes accuracy and precision. For laser diffraction, there are several parameters that should be optimized to ensure good results. These include: stirrer rate/air pressure (wet/dry method), ultrasonication frequency and duration for particle dispersion, measurement time, obscuration levels and optical parameters. It is essential that the user examines the effects of these parameters on the measured values for the instrument used, particularly when studying materials such as SCMs which are diverse in physicochemical properties.

For the laser diffraction unit used in this study, the values of the analytical parameters were varied in order to determine the most appropriate value of each parameter based on the changes to $d_{\mathrm{v}} 10, d_{\mathrm{v}} 50$, and $d_{\mathrm{v}} 90$ for the materials tested. These percentile diameters $d_{\mathrm{v}} 10, d_{\mathrm{v}} 50$ and $d_{\mathrm{v}} 90$ represent the size (in micrometers) below which 10,50 or $90 \%$, respectively, of the sample falls. The procedure of the determination of the instrumentation parameters for wet measurements is demonstrated for the blast furnace slag only (sample BFS1). Blast furnace slag was chosen since it has irregularly shaped but chemically homogeneous particles (Fig. 2B), and thus provides a relatively well-characterized deviation from the assumptions inherent in the technique. A similar procedure was followed for evaluation of the fly ash as presented in Ref. [26]. According to Arvaniti et al. [26] the measurement parameters used for fly ash were: 2 min sonication time, $20 \mathrm{~s}$ measurement time, 1,700 rpm stirrer rate, 15-25\% obscuration limits, and two pairs of optical parameters: $n=1.65, k=0$ or 0.001 and $n=1.73, k=0$ or 0.001 , where $\mathrm{n}$ and $\mathrm{k}$ are the real and the imaginary parts of the complex index of refraction.

3.4.1.1 Wet dispersion Isopropanol was used as a dispersant since it does not react with slag. Different sonication times were used and the $d_{\mathrm{v}} 10, d_{\mathrm{v}} 50$ and $d_{\mathrm{v}} 90$ before and after sonication are shown in Fig. 6A. De-agglomeration of the particles is observed after $2 \mathrm{~min}$ in the ultrasonic bath, and after longer durations of sonication (4-6 min) the $d_{\mathrm{v}} 10$ and $d_{\mathrm{v}} 50$ essentially stabilize, while fluctuations occur in $d_{\mathrm{v}} 90$ because of re-agglomeration. An ultrasonication time of $2 \mathrm{~min}$ was chosen as the ideal condition to disperse the slag (BFS1) used in this study.

3.4.1.2 Stirring speed Figure 6B shows the particle size distribution changes when using different stirrer rates in the laser diffraction instrument. Each point shown on the plot corresponds to a single measurement, and six consecutive measurements were taken for each stirrer rate. At low rates $(500 \mathrm{rpm})$ the particle sizes are lower than observed when increasing the stirring rate. This is consistent with the fact that a slow stirring rate does not provide the force required to suspend the larger particles within the sample. The observed increase in $d_{\mathrm{v}} 90$ at higher stirrer rates $(3,000 \mathrm{rpm})$ could be attributed to the formation of bubbles in the dispersant. From 1,000 to $2,500 \mathrm{rpm}$, the particle sizes are relatively stable, indicating that the particles are correctly presented into the measurement cell. The stirrer rate is therefore recommended to be set at a value at the center of this range (i.e. at around 1,700 rpm for this example), which also agrees with the suggestions in [27].

3.4.1.3 Measurement time To verify the effect of the duration of measurements, particles were analyzed using measurement times of 10, 20, 30 and $40 \mathrm{~s}$. Figure $6 \mathrm{C}$ shows that the measurement time does not have an effect on the values of $d_{\mathrm{v}} 10$ and $d_{\mathrm{v}} 50$. However, a slight fluctuation is noticeable in $d_{\mathrm{v}} 90$ 
Fig. 6 Variation of the particle size fractions of anhydrous blast furnace slag dispersed in isopropanol as function of: A the time of ultrasonication. Stirring speed: $1,700 \mathrm{rpm}$; obscuration: $10-15 \%$; measurement time: $20 \mathrm{~s}$; $n=1.62, k=1, \mathbf{B}$ the stirrer rate. Sonication time: 2 min; obscuration: 10-15\%; measurement time: $20 \mathrm{~s} ; n=1.62, k=1$, $\mathrm{C}$ the measurement time. Sonication time: $2 \mathrm{~min}$; obscuration: $10-15 \%$; measurement time: $20 \mathrm{~s}$; $n=1.62, k=1, \mathbf{D}$ the obscuration titration values. Sonication time: $2 \mathrm{~min}$; stirrer rate: $1,700 \mathrm{rpm}$; measurement time: $20 \mathrm{~s}$; $n=1.62, k=1$

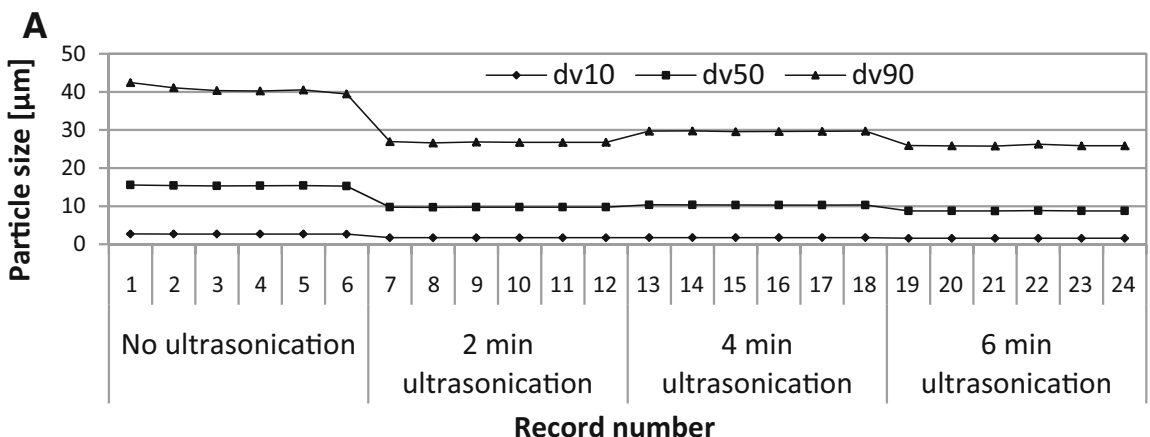

B

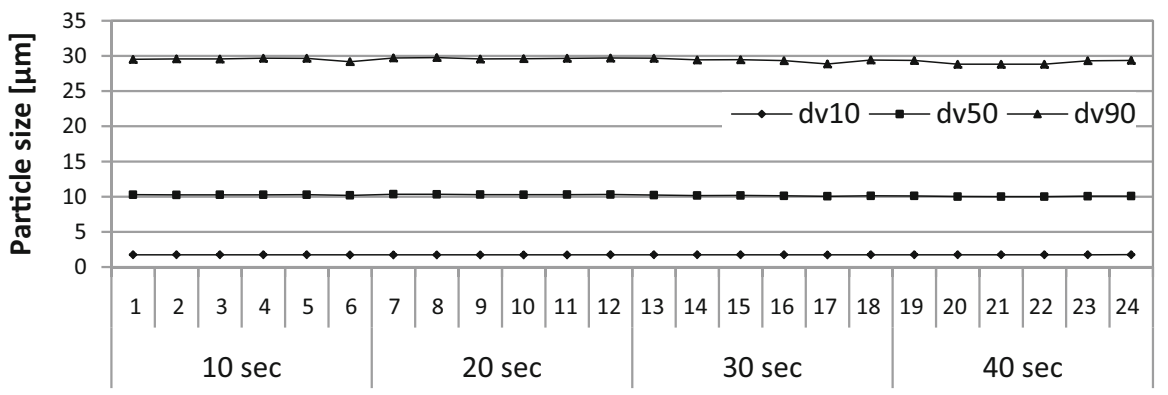

Record number
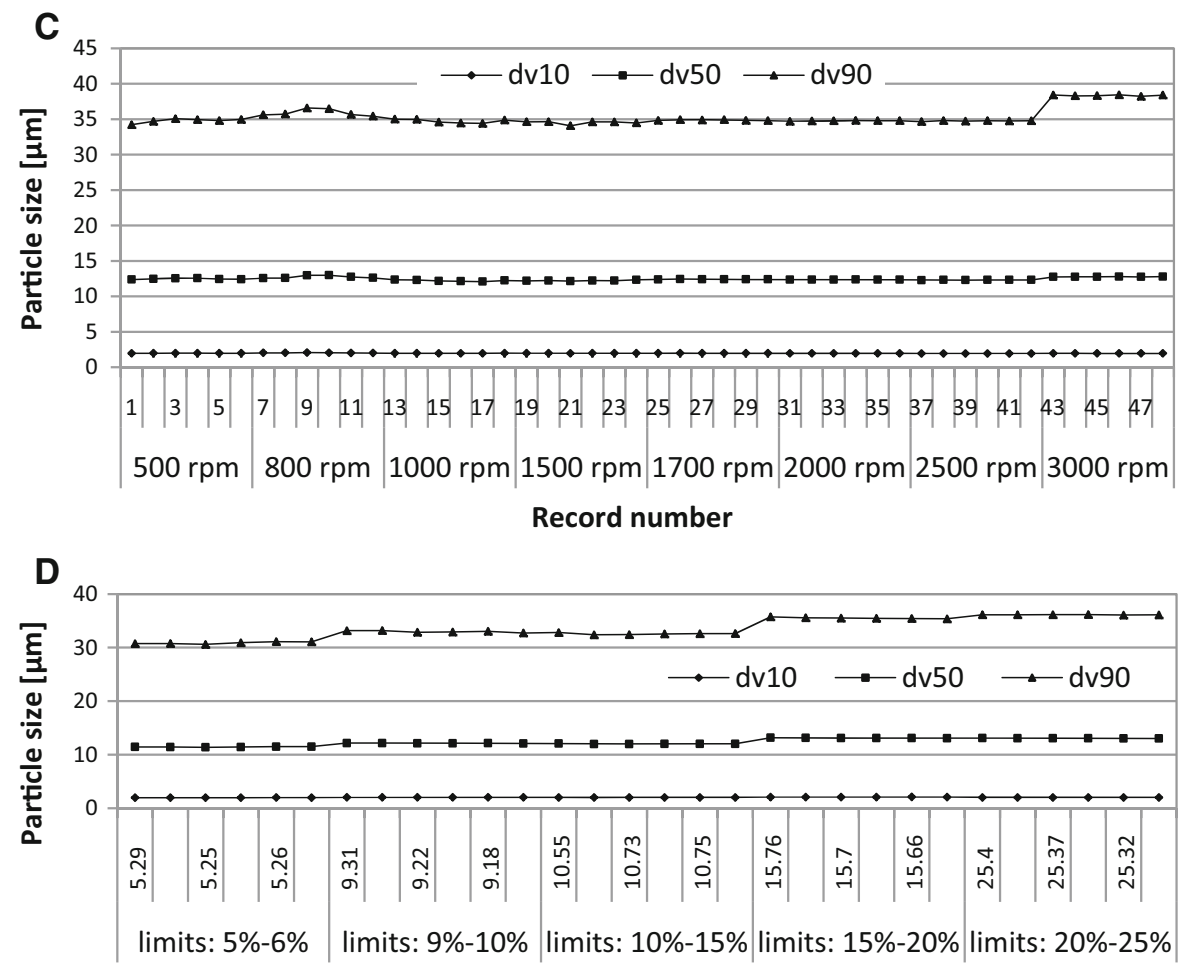

Obscuration [\%] across the whole range of measurement times. Based on these data, a standard measurement time of $20 \mathrm{~s}$ was chosen.
3.4.1.4 Sample concentration The obscuration rate defines the quantity of the sample that is added in the measurement cell. If the amount of sample added to 
Fig. 7 Influence of optical parameters on calculated $d_{\mathrm{v}} 10, d_{\mathrm{v}} 50$ and $d_{\mathrm{v}} 90$ for BFS1 sample. Sonication time: $2 \mathrm{~min}$; stirrer rate: 1,700 rpm; measurement time: $20 \mathrm{~s}$; obscuration limits: $9-15 \%$
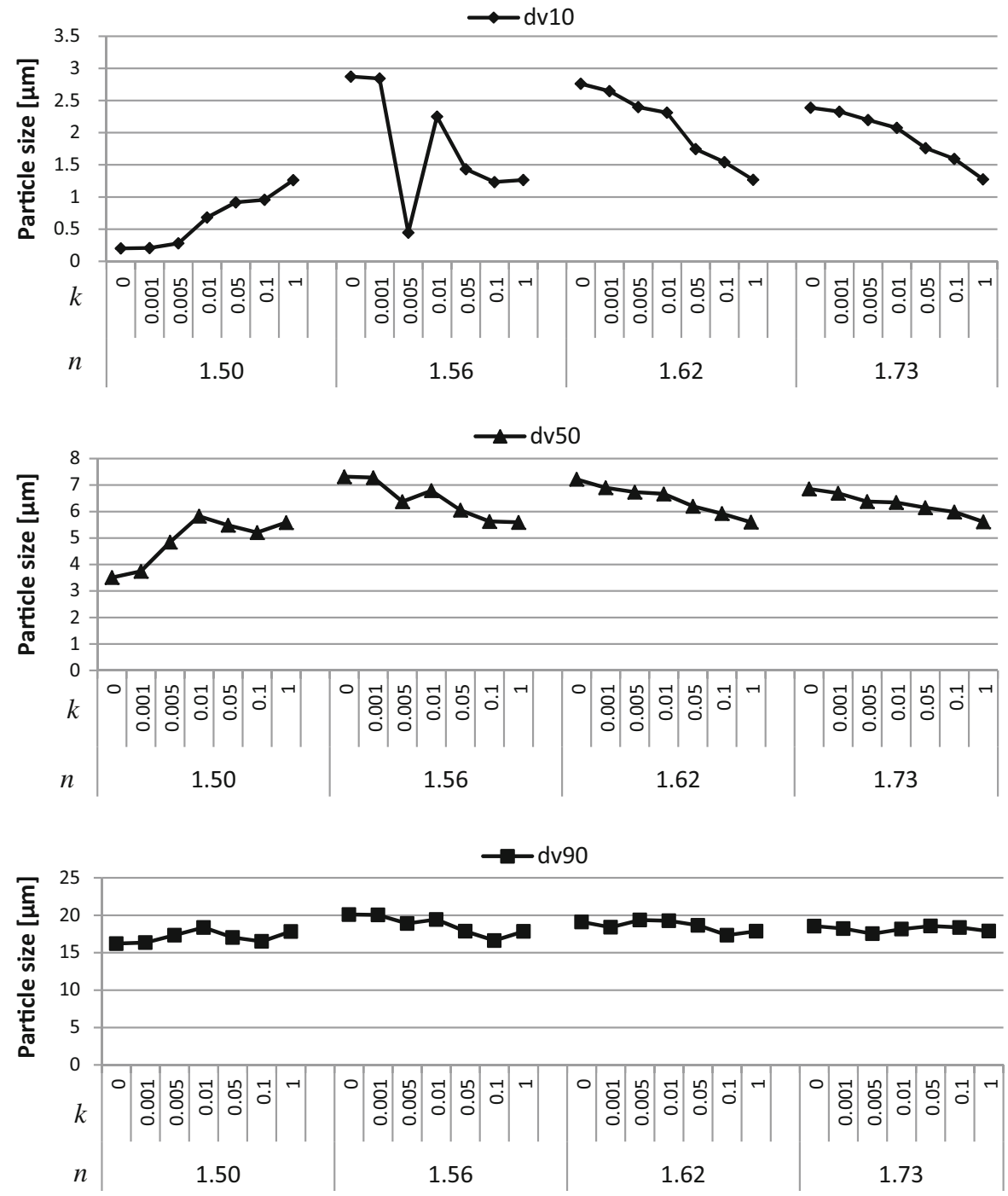

the dispersion unit is too low then the results will not be reproducible due to a low signal to noise ratio. If the obscuration is too high then the measurement becomes affected by multiple scattering, causing a reduction in the measured particle size at higher obscurations. An obscuration titration was carried out, and the measured particle size parameters as a function of obscuration are shown in Fig. 6D. The limits were set as indicated in Fig. 6D (e.g. limits of 5-6\% mean that a fraction of $5-6 \%$ of the light is lost from the main beam when the sample is introduced), and the sample was added until a value in between these limits is reached. Then the particle size measurements started automatically. Increased obscuration limits seem to increase the particle size of $d_{\mathrm{v}} 90$ and $d_{\mathrm{v}} 50$, but it does not seem to have a significant effect in the $d_{\mathrm{v}} 10$ values.

Based on the fact that the particle size should be independent of the obscuration within a given concentration range, the limits $9-15 \%$ showing the minimum fluctuations of the results were chosen.

\subsubsection{Influence of optical parameters on particle} size analysis The light scattering data obtained from the measurements were analyzed using the Mie model. Since there are not many data available in the literature concerning the optical properties of the slags used in cements and concretes, the refractive indices published for cement and other cementitious 
materials were used. The raw data from laser diffraction were analyzed using the real refractive indices, $n: 1.50,1.56,1.65$ and 1.73 and the imaginary absorption coefficients, $k$ : 0, 0.001, 0.005, 0.01, 0.05, 0.1 and 1. Each $n$ was combined with each $k$ giving a total of 28 optical models which were used for analysis. The corresponding results are shown in Fig. 7. Each point corresponds to one optical model.

Using different $n$ and $k$ values modifies the size of the smaller particles registered $\left(d_{\mathrm{v}} 10\right.$ and $\left.d_{\mathrm{v}} 50\right)$ in the slag analyzed. Using a small refractive index $(n=1.50)$, higher particle sizes are registered with increased $k$ values. Conversely, when increasing the assumed refractive index from 1.56 to 1.73 , higher $k$ values tend to reduce the particle size. This effect is more evident in the $d_{\mathrm{v}} 10$ fraction. The significant variation in the particle size recorded using different optical parameters highlights the importance of detailed optical characterization of the SCMs prior to laser diffraction analysis to ensure that the particle size distribution results are representative.

The volume weighted percentiles $d_{\mathrm{v}} 10, d_{\mathrm{v}} 50, d_{\mathrm{v}} 90$ and the specific surface area were measured using the LD method with the appropriate parameters for the different materials. For FA1 sample specific surface area is higher than the Blaine surface area and lower than BET surface area. FA2 sample gave lower SSA when measured with LD method (Table 4) compared to the Blaine and BET surface area. The $d_{\mathrm{v}} 10, d_{\mathrm{v}} 50$ and $d_{\mathrm{v}} 90$ that are measured for each fly ash sample using different optical parameters show slightly different results which are more profound for FA1 sample.

Blast furnace slag samples give much lower SSA when measured by LD, than when measured by BET and Blaine. By changing the absorption index from $k=0$ to $k=0.1$, the calculated SSA is doubled and the particle size is lower. The optical parameters were chosen based on the results illustrated in Fig. 7. The parameters $n=1.56$ and $k=0$ or $k=0.1$ give the most stable results for $d_{\mathrm{v}} 10, d_{\mathrm{v}} 50$ and $d_{\mathrm{v}} 90$.

In the case of SF the determination of PSD by LD method gave a bimodal distribution (Fig. 8). The calculated SSA was much lower than the BET surface area. The large particles $\left(d_{\mathrm{v}} 10, d_{\mathrm{v}} 50, d_{\mathrm{v}} 90\right)$ identified in the SF sample could be the result of insufficient dispersion of the sample before the measurement.

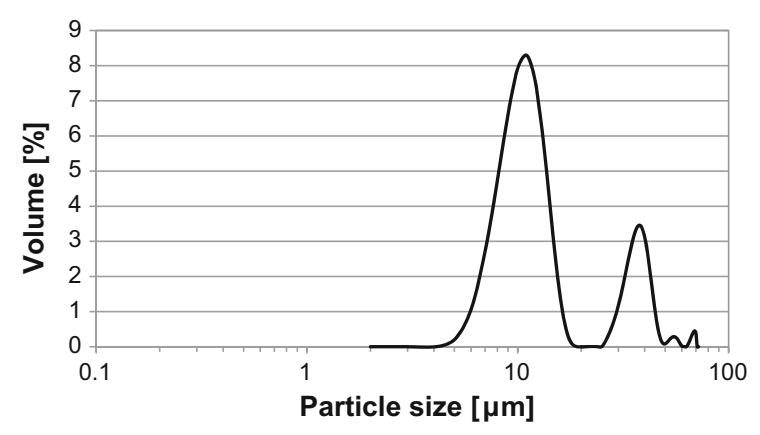

Fig. 8 Particle size distribution of SF as determined by laser diffraction. Sonication time: $55 \mathrm{~min}$; stirrer rate: 2,000 rpm; measurement time: $20 \mathrm{~s}$; obscuration limits: $5-10 \% ; n=1.53$, $k=0.001$
Table 4 Volume weighted percentiles, specific surface area and R45 for fly ash, blast furnace slag and silica fume samples calculated by using different optical parameters

Samples were measured with the LD method

\begin{tabular}{|c|c|c|c|c|c|}
\hline & $d_{\mathrm{v}} 10$ & $d_{\mathrm{v}} 50$ & $d_{\mathrm{v}} 90$ & $\mathrm{R} 45(\%)$ & $\operatorname{SSA}\left(\mathrm{m}^{2} / \mathrm{kg}\right)$ \\
\hline \multicolumn{6}{|l|}{ FA1 } \\
\hline $\mathrm{RI}=1.65, \mathrm{AI}=0.001$ & 3.068 & 11.215 & 62.699 & 15.19 & 384 \\
\hline $\mathrm{RI}=1.73, \mathrm{AI}=0.001$ & 2.800 & 10.869 & 61.768 & 14.87 & 415 \\
\hline \multicolumn{6}{|l|}{ FA2 } \\
\hline $\mathrm{RI}=1.65, \mathrm{AI}=0.001$ & 4.296 & 14.944 & 53.907 & 14.05 & 279 \\
\hline $\mathrm{RI}=1.73, \mathrm{AI}=0.001$ & 4.110 & 14.719 & 53.633 & 13.90 & 293 \\
\hline \multicolumn{6}{|l|}{ BFS1 } \\
\hline $\mathrm{RI}=1.56, \mathrm{AI}=0.1$ & 1.233 & 5.625 & 16.618 & 0.26 & 682 \\
\hline $\mathrm{RI}=1.56, \mathrm{AI}=0$ & 2.873 & 7.316 & 20.090 & 0.30 & 370 \\
\hline \multicolumn{6}{|l|}{ BFS2 } \\
\hline $\mathrm{RI}=1.56, \mathrm{AI}=0.1$ & 1.173 & 6.402 & 19.717 & 0.45 & 640 \\
\hline $\mathrm{RI}=1.73, \mathrm{AI}=0.001$ & 2.262 & 7.544 & 20.950 & 0.42 & 402 \\
\hline \multicolumn{6}{|l|}{$\mathrm{SF}$} \\
\hline $\mathrm{RI}=1.53, \mathrm{AI}=0.001$ & 0.187 & 0.418 & 19.090 & 4.07 & 6,180 \\
\hline
\end{tabular}


Although the sonication time was extended to $55 \mathrm{~min}$ it was impossible with isopropanol to get separated single particles. For particles smaller than $1 \mu \mathrm{m}$, it is difficult to overcome the Van Der Waals forces and get particles separated.

The R45, which represents the percentage of material which should be retained on a no. 325 $(45 \mu \mathrm{m})$ sieve, was also calculated by the LD method. Comparing the results in Table 4 with those obtained using the wet sieving method, only the FA2 sample gives calculated (LD method) values close to the measured (wet sieving method) ones. For the other samples, except silica fume which was not measured by wet sieving, the calculated values are lower than the measured ones.

\subsection{Particle size and shape by image analysis}

The volume weighted percentiles $d_{\mathrm{v}} 10, d_{\mathrm{v}} 50, d_{\mathrm{v}} 90$ of two samples of blast furnace slag (BFS1) performed via static image analysis (SIA) are reported in Table 5; $d \mathrm{v}_{\text {MAX }}$ corresponds to the largest particle identified. The corresponding cumulative curve of this material is shown in Fig. 9.

Table 5 Volume weighted Xth percentiles of the particle diameter of BFS1 obtained by SIA

\begin{tabular}{llr}
\hline Percentile & Series 1 & Series 2 \\
\hline$d_{\mathrm{v}} 10(\mu \mathrm{m})$ & 10.66 & 9.00 \\
$d_{\mathrm{v}} 50(\mu \mathrm{m})$ & 35.00 & 35.06 \\
$d_{\mathrm{v}} 90(\mu \mathrm{m})$ & 65.30 & 64.65 \\
$d_{\mathrm{vMAX}}(\mu \mathrm{m})$ & 99.44 & 95.75 \\
\hline
\end{tabular}

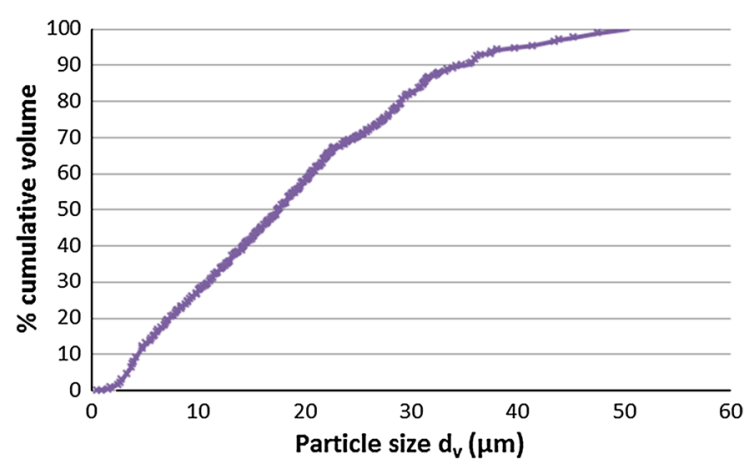

Fig. 9 Particle size distribution of BFS1 as determined by image analysis
From image analysis, particle shape parameters such as elongation and bluntness can easily be calculated. The particle elongation appears to be quite low with $90 \%$ of the particles getting an elongation ratio lower than 0.40 . Regarding particle bluntness, it is necessary to consider narrow size fractions because the numbers of pixels involved in the calculation of this parameter will strongly impact the results. For the same reason, it is not relevant to calculate bluntness from a particle with less than 100 pixels. Figure 10 shows that some particles look rounded and blunt while others are rougher. However, apparent roughness may result from the blind analysis of two touching particles as shown in Fig. 10 (left hand bottom corner). In such case, an additional filtering may be necessary. The diameter of the red disk is proportional to the area of the particle. The "O.Bluntness" refers to Occhio's definition of bluntness [28].

Differences between PSD and SIA results are usually attributed to insufficient dispersion of the fine particles in the case of SIA, or inaccuracies in the optical model in the case of laser diffraction [29]. In this study, different optical models were used when analyzing the particle size of the slag via laser diffraction, and the results derived from this technique are three times smaller than the ones obtained applying SIA.

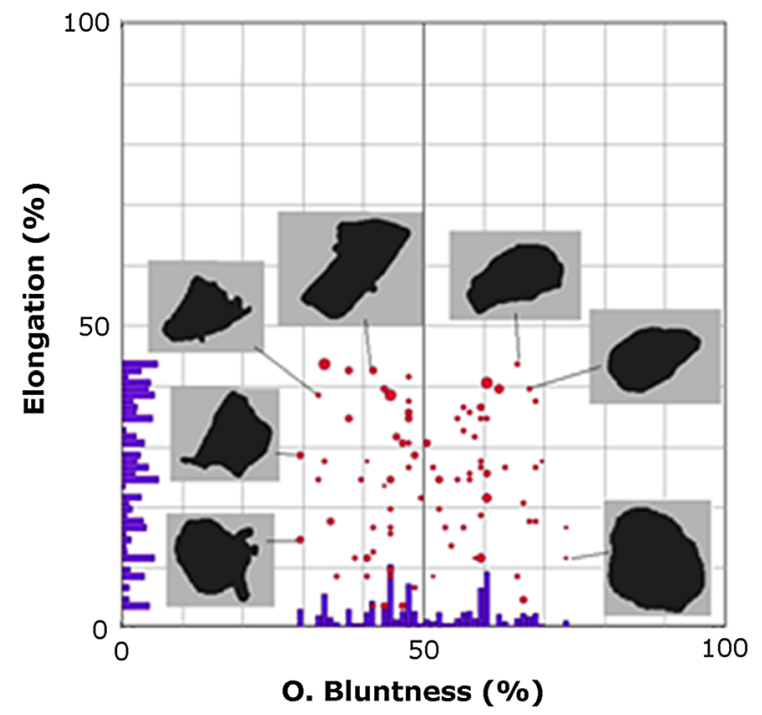

Fig. 10 Shape analysis of BFS1 particles, size fraction $>25 \mu \mathrm{m}$ 
3.6 Particle size distribution determined using MIP

Limitations of the MIP technique are evident where considering a substance where inter- and intra-particle voids are of a similar size, and distinction between the volume of mercury intruded into the pores of the particle, and into the spaces between the particles cannot practically be made. However, for the majority of powder samples, it may be expected that while their inter-particle voids may be high (spaces between particles), their intra-particle voids (spaces within particles) are typically small; and hence, the distinction tends to be simple.

Mercury intrusion does not measure particle sizes in the way that techniques such as laser diffraction and image analysis do. In the MIP technique it is assumed that particles have the same shape, which is spherical, and that they are evenly packed. The mean particle size is estimated by the pressure it takes to fill the interstitial volume with mercury. In other words, the particle size distribution derived from this method is the size distribution of spheres that, when applied to the mathematical model, most closely reproduce the experimental penetration data. The size unit is 'equivalent spherical size'.

Results obtained from MIP analysis of the fly ash, blast furnace slag and silica fume are shown in Fig. 11. The PSD graphs indicate a predominant particle size around the 5-10 $\mu \mathrm{m}$ range for FA1 (Fig. 11A), FA2 (Fig. 11B), BFS1 (Fig. 11C) and BFS2 (Fig. 11D) samples. The silica fume PSD indicates a predominant particle size centring around the $100-200 \mathrm{~nm}$ (Fig. 11E). Comparing the results for SF from LD (Fig. 8) and MIP (Fig. 11), it can be seen that in the first method there is a bimodal distribution and the measured particles have a predominant size of $10 \mu \mathrm{m}$, whereas in the second method smaller particles of $0.1 \mu \mathrm{m}$ are measured. In all the samples analyzed, the PSD peaks were sharply defined, suggestive of a rather
Fig. 11 Particle size distribution of A BFS1, B BFS2 and C FA1, D FA2 and E SF samples using MIP

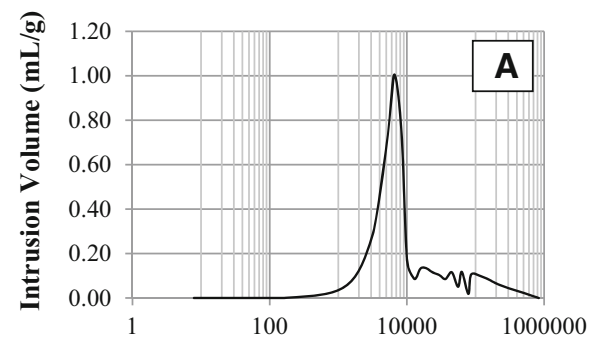

Particle equivalent spherical size dia.(nm)

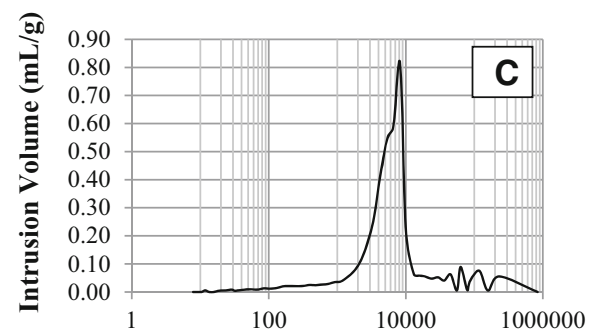

Particle equivalent spherical size dia.(nm)

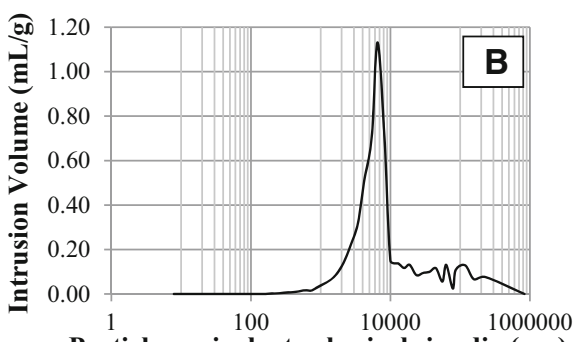

Particle equivalent spherical size dia.(nm)

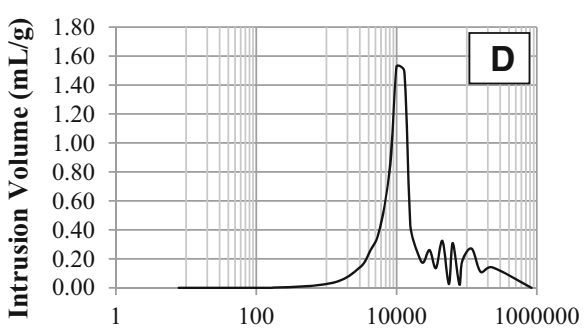

Particle equivalent spherical size dia.(nm)

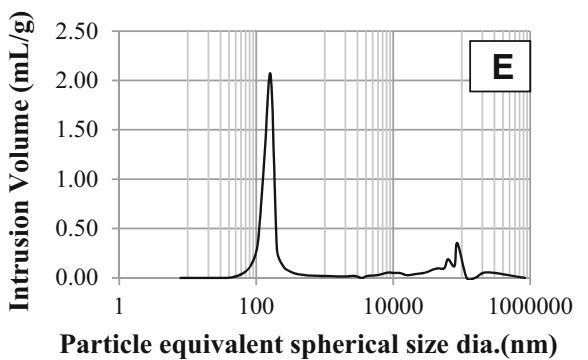


monosized (relative to the size spectrum) particle arrangement.

\subsection{Implications}

It is elucidated that there is a significant disagreement in the results obtained for SCMs when using the different methodologies developed for Portland cements for the determination of the specific surface area (Blaine fineness and BET), and particle size distribution (laser diffraction, image analysis and MIP). The differences in the results among the techniques used in this study are mainly associated with the intrinsic properties of the SCMs assessed, such as inter-particle heterogeneity, shape and porosity, the required pre-conditioning of the specimens, and the assumptions that each of these techniques required. So, it is important to understand the limitation of each techniques and the meaning of the results obtained, in order to select the most appropriate technique to characterize SCMs.

In some applications, such as assessing superplasticizer consumption, it is the surface area as determined by BET that is needed, while in other areas, such as determination of reaction rate, the reactive particle surface area, such as the determined by techniques that consider the particle size and shape, such as laser diffraction, image analysis and MIP, is more important than the total surface area of the material that can be calculated by BET (i.e., surface area contributed by components such as unburned carbon in fly ashes should not be considered). For this reason it is of great significance to understand which definition of surface area is actually needed for a specific application to select a characterization method on this basis.

\section{Conclusions}

SCMs are widely used in the concrete and cement industry not only because they provide economic and environmental benefits, but also because their use improves the performance of concrete. Specific surface is one of the most important parameters for the optimization of SCMs utilization in concrete. There are several techniques that are currently used for the determination of the particle size distribution and specific surface area of SCMs. Most of them are standardized methods for the physical characterization of Portland cement. Since SCMs have shape and size peculiarities associated with their production process, which differentiate them from Portland cement, these techniques may not be directly applicable to SCMs. Moreover, instrument limitations, poor calibration and incorrect optical parameters may result in deviations from expected results. However, it must be realized that particle size analysis is not usually an objective in itself, but rather is a means to correlate powder properties with some process of manufacture, usage or preparation.

The specific surface and particle size distribution of some commercially available fly ashes, blast furnace slags and silica fume were measured using several techniques presented in this study, and the following conclusions are drawn:

- Materials should be adequately dispersed before testing, specifically via sieving and laser diffraction, as misleading results are obtained when agglomeration of particles takes place.

- When applying an air permeability method to the SCMs, problems occur during the procedure related to the difficulty to form a good compacted bed of specific porosity, especially in finer SCMs such as silica fume. Utilization of a modified plunger does not seem to induce significant changes in the SSA results obtained; however, it does facilitate the evaluation of SCMs.

- For particles that are porous, or have a rough surface structure, such as fly ash and blast furnace slag, the BET surface area is found to be greater than the Blaine surface area.

- Wet sieving overestimated the fraction retained on the $45 \mu \mathrm{m}$ sieve, because agglomerated particles remained on the sieve. The wet sieving method could not be used for silica fume, since the criteria established for this method are only valid for fly ash and natural pozzolans.

- For the wet LD technique a method was developed for the measurement of SCMs. The optimized parameters for the sample of blast furnace slag are demonstrated in this study. The analysis presented here indicated that results obtained by LD method are strongly influenced by the optical parameters of the material that is measured.

- Analysis of microscope images of blast furnace slag gave particle sizes three times larger than the ones obtained by laser diffraction. 
- MIP is presented as a potential method for the determination of particle size distribution of SCMs. The particle size distribution derived from this method is the size distribution of spheres that, when applied to the mathematical model, most closely reproduce the experimental penetration data. Considering this, MIP could be a suitable technique to determine the PSD of fly ashes.

- Accuracy can be difficult to define for size analysis of non-spherical particles; all sizing techniques give different answers. For irregularly shaped particles, characterization of particle size must include information on particle shape.

\section{References}

1. Lothenbach B, Scrivener K, Hooton RD (2011) Supplementary cementitious materials. Cem Concr Res 41(12): 1244-1256

2. Snellings R, Mertens G, Elsen J (2012) Supplementary cementitious materials. Rev Mineral Geochem 74:211-278

3. Siddique R, Khan MI (2011) Supplementary cementing materials. Springer, Berlin. ISBN 978-3-642-17865-8

4. Juenger M, Provis JL, Elsen J, Matthes W, Hooton RD, Duchesne J, Courard L, He H, Michel F, Snellings R, Belie ND (2012) Supplementary cementitious materials for concrete: characterization needs. MRS proceedings 1488. doi:10.1557/opl.2012.1536

5. Arvaniti EC, Juenger MCG, Bernal SA, Duchesne J, Courard L, Leroy S, Provis JL, Klemm A, Belie ND (2014) Physical characterization methods for supplementary cementitious materials. Mater Struct. doi:10.1617/s11527014-0430-4

6. EN 196-6 (2010) Methods of testing cement-part 6: determination of fineness

7. ASTM C430-08 (2008) Fineness of hydraulic cement by the 45- $\mu \mathrm{m}$ (No. 325) Sieve

8. EN 451-2 (1995) Method of testing fly ash-part 2: determination of fineness by wet sieving

9. ASTM C204-11 (2011) Standard test methods for fineness of hydraulic cement by air-permeability apparatus

10. ISO 13320:2009 (2009) Particle size analysis-laser diffraction methods. Part I: general principles

11. ISO 9277 (2010) Determination of the specific surface area of solids by gas adsorption-BET method
12. ISO 13322-1 (2010) Particle size analysis-image analysis methods-part 1: static image analysis methods

13. Mayer RP, Stowe RA (1965) Mercury porosimetrybreakthrough pressure for penetration between packed spheres. J Colloid Sci 20:893-911

14. Mayer RP, Stowe RA (2005) Packed uniform sphere model for solids: interstitial access opening sizes and pressure deficiencies for wetting liquids with comparison to reported experimental results. J Colloid Interface Sci 294:139-150

15. Hewlett P (2003) Lea's chemistry of cement and concrete, 4th edn. Butterworth Heinemann, Lodon

16. EN 196-2 (2005) Methods of testing cement-part 2: chemical analysis of cement

17. EN 451-1 (2004) Fly ash for concrete-part 1: definition, specifications and conformity criteria

18. EN 197-1 (2000) Cement-part 1: composition, specifications and conformity for common cements

19. Malvern MAN 0396 Issue 1.0 (2007) Sample dispersion and refractive index guide. Mastersizer 2000

20. Gregoire MP, Dislaire G, Pirard E (2007) Accuracy of size distributions obtained from single particle static digital image analysis. In: Proceedings of Partec conference. Nürenberg 2007, p 4

21. Michel F, Gregoire M, Pirard E (2007) Size distribution of powders in range of $1-100 \mu \mathrm{m}$ : a comparison of static digital image analysis and laser diffraction. In: Proceedings of Partec conference. Nürenberg 2007, p 4

22. León CA (1998) New perspectives in mercury porosimetry. Adv Colloid Interface Sci 76-77:341-372

23. ASTM C618-12a (2012) Standard specification for coal fly ash and raw or calcined natural pozzolan for use in concrete

24. ASTM C989/C989 M-13 (2013) Standard specification for slag cement for use in concrete and mortars

25. Teipel U, Winter H (2011) Characterization of the specific surface area with the permeation method. In: At mineral processing 52

26. Arvaniti EC, Belie ND (2014) Method development for the particle size analysis of supplementary cementitious materials. In: XIII DBMC, Sao Paulo, Brazil, 2-5 Sept 2014 (to be published)

27. Quercia G, Hüsken G, Brouwers HJH (2012) Water demand of amorphous nano silica and its impact on the workability of cement paste. Cem Concr Res 42(2):344-357

28. Leroy S, Dislaire G, Bastin D, Pirard E (2011) Optical analysis of particle size and chromite liberation from pulp samples of a UG2 ore regrinding circuit. Miner Eng 24:1340-1347

29. Tinke AP, Carnicer A, Govoreanu R, Scheltjens G, Lauwerysen L, Mertens N, Vanhoutte K, Brewster ME (2008) Particle shape and orientation in laser diffraction and static image analysis size distribution analysis of micrometer sized rectangular particles. Powder Technol 2(186):154-167 